\title{
Bachelor of Science in Law
}

National Cancer Institute

\section{Source}

National Cancer Institute. Bachelor of Science in Law. NCI Thesaurus. Code C71352.

A special-purpose degree that allows someone who has some prior studies but not achieved a bachelor's degree to resume their education and pursue the study of law towards an eventual Juris Doctor degree. 